\title{
Pío Baroja, ese pequeño buscador de almas
}

\section{El médico y el escritor}

El escritor vasco fue, sin duda ninguna, un médico que contemplaba con desgana el mundo, retratándolo en sus apresuradas páginas. En este sentido, aportó una reflexión interesante, tanto en la teoría, como en la práctica, sobre la novela. Así lo hace al parecer en muchas de sus obras, como La nave de los locos. En La busca también nos da pistas, pues vemos cómo empieza un capítulo y de pronto se detiene, entrando en persona y afirmando que ese tipo de párrafos son buenos para el folletín francés, continuando tras punto y aparte con un estilo más personal. Nos enseña sus trucos para penetrar en el alma humana, extraña generosidad en los prestidigitadores. En Camino de perfección, hablando el narrador en primera persona, se pregunta si tiene en sus manos un manuscrito o cartas, formas de entrar en la intimidad de sus criaturas, de sí mismo. Y así, sus indagaciones sobre el personaje y el punto de mira del narrador, son novedosas. Recordemos en El mundo es ansí cómo comienza la primera parte con el mismo autor como narrador, incluso iniciando en primera persona, cómo continúa en la segunda con cartas de la protagonista, concluyendo en la tercera con ésta como narradora. Consigue irnos introduciendo en el alma rusa de Sacha, que conocía a través de sus admirados Tolstoi y Dostoievski. Desenmascara así a sus personajes, pues éstos van cubiertos como toda persona, como un comediante en el teatro.

Recordemos también las memorias del literato aficionado de La sensualidad pervertida, que se ha entregado al «placer melancólico del recuerdo». Se nos presenta, tal como es definido, un pequeño buscador de almas. Se trata de su propia autobiografía, pues, si en la nota preliminar de editor de 1954 se enmascara de nuevo, sus afirmaciones son rotundas: «Cada cual obtiene de la vida un resultado, cuando lo obtiene, y estas cuartillas son el mío». O bien: «Supongo que mi vida debe tener su unidad, y la unidad de mi vida hará la unidad de esta historia». Son certeras también sus reflexiones sobre la relación entre vida y literatura, al decir que para que una vida tenga principio, desarrollo y fin, tienen que malograrse miles, millones, que no tienen uno u otro. Pero la literatura es eso, darle fin a lo que no lo tiene, principio a lo que carece de él. El literato supone que una vida tiene unidad, pero ésta procede de la intención del biografiado o del biógrafo, que proporcionan una coherencia vital. También sugiere sobre la forma de cincelar una biografía, o bien una autobiografía: «Claro que si fuera un artista, un escritor hábil, elegiría unos episodios, suprimiría otros, inventaría algunos; pero no lo soy, y no pienso escribir más que mis 
recuerdos, por un vulgar orden cronológico». El tiempo es el que transforma todo, dando relieve o borrando sucesos. Añadirá comentarios y reflexiones de hoy a su infancia y juventud, si pretendiera añadir los de entonces, sería obra de artificio, «y yo no soy hábil para el artificio». Se dispone a mostrarnos la vida, su vida a la buena de Dios, en vulgar orden cronológico.

Junto al novelista, el médico, por quien Pedro Laín y Luis S. Granjel se han interesado. Ha contado Baroja con frecuencia sus estudios y su vida, en memorias, novelas, discursos y ensayos. Su desprecio por el profesorado, su falta de afición por el estudio. También sus enfrentamientos psicológicos con el dolor. Primero, en la sala de disección, en la que se profana algo sagrado, como el cuerpo humano. Se justifica tanto por el espíritu atávico destructor del ser humano, como por su curiosidad científica -inquisitorial, nos dice- por conocer la vida y la muerte. Segundo, en los hospitales, en el aprendizaje de la patología y su clínica. Los hospitales le afectan, sean las enfermas de venéreas, sean los hombres y más las mujeres que como enfermos y presos son maltratados por los profesionales y las instituciones. En Aurora roja insistirá en esa mezcla de amor y muerte, al describir los degradados barrios que rodean algunos cementerios madrileños. Además, ese pequeño buscador de almas se interesa más que por las enfermedades, por la psicología de esos enfermos, sus dolores y sus sentimientos. Su experiencia se amplía en Cestona, donde empieza a amar las costumbres y las artes propias, entrando en temas antropológicos que pasarán a sus novelas y, más tarde, a Julio Caro Baroja. También, en tercero, las muertes cercanas, así la de su hermano. Las muertes en familia de Luisito y Adelita -por tuberculosis- las hace sobresalir en las páginas de sus narraciones. La culpa y el deseo -el amor y la muerte- se entrecruzan en estas muertes próximas.

No es extraño, en cuarto lugar, que su tesis verse sobre El dolor. Leída ante Gómez Ocaña, San Martín y Cajal, supone una puesta al día desde diversos puntos de vista de un tema de primera importancia, para Baroja -y así eran entonces las tesis doctorales- no suponía verdadera investigación. O quizá sí, pues al fin de su carrera el protagonista de El árbol de la ciencia se dedica con pasión a revisiones bibliográficas para una revista, que Iturrioz le consigue. El dolor será el gran tema de muchas de las novelas barojianas y precisamente esa piedad ante el dolor -que considera muy española- es un timbre de gloria de su personalidad. El dolor individual y social será siempre mostrado en sus novelas. Será necesario para describir en sus páginas posteriores a muchos seres sufrientes, enfermos, hambrientos, explotados, agonizantes... También el dolor del sabio y del artista, el dolor de quien penetra en un recinto sagrado y es culpado y penado. Es el dolor de Adán y Eva al conocer en el Génesis el árbol de la ciencia, o de la sexualidad. Es el dolor que el Eclesiastés quiere impedir cuando dice que añadir sabiduría supone dolor, afirmación citada en la tesis barojiana. 


\section{Golfos, delincuentes y prostitutas}

Para mostrar ese dolor utilizará la ciencia, de la que había sido mal estudiante, pero fue buen lector. Ciencia en la que encuentra dos grandes trazados sobre la historia de la humanidad, quizá mitos, quizá paradigmas. Por un lado, el de la degeneración. Proviene del conde de Buffon, quien vio que los animales en cautividad decaían. Pasa esta observación por la fisiología y la patología, surgiendo en Francia la llamada escuela de los «degeneracionistas», con Morel y Magnan a la cabeza. Es un pensamiento latino, aristocrático, católico, estando Adán y Eva detrás, pues desde un origen paradisíaco caen por su pecado en la culpa, el trabajo y la muerte. Por otro, la lucha por la vida, que servirá de título a una de las trilogías barojianas. Darwin vio cómo los pájaros, también aislados, cambiaban y formula la teoría de la evolución. Es una teoría del norte, protestante, burguesa, que muestra las pruebas que la vida impone, llegando al final por selección y lucha al hombre blanco civilizado. Junto al biólogo, está su pariente Francis Galton. Y apoyando de forma sacra el mito de Hércules, quien consigue pasar de héroe a dios con sus trabajos, liberando a Prometeo que nos entregó el fuego y el saber. Quienes no lleguen a estas alturas, o hayan caído en degeneración, son condenados: así los delincuentes, salvajes, colonizados, enfermos, locos e incluso el hombre de genio. Nietzsche, desde luego, conocía bien la degeneración y el superhombre, y era leído por Pío Baroja. También le era bien conocido a éste Cesare Lombroso, que con todos estos mimbres construye la teoría del «criminal nato», el delincuente es ese salvaje primitivo que ha degenerado o no ha alcanzado la civilización.

Lector también de Spencer, pensaba Pío Baroja que las leyes biológicas y sociales determinan el mundo. No son raras en él las clasificaciones biologicistas, que comienza Iturrioz. Iberos y semitas, celtas y bereberes, gorilas y chimpancés, dolicocéfalos y braquicéfalos son formas de describir a los grupos humanos, que lo acercan a sus lecturas del aristócrata Gobineau. Las aplicará en su trilogía 'La lucha por la vida' a un mundo de personas condenadas. Pero también aplicará sus muchas lecturas. Ricardo Senabre ha señalado como fuentes la picaresca, los bajos fondos de Dickens y de Eugène Sue. El mismo Baroja lo acepta y también insiste una y otra vez en el amplio panorama social de Balzac y sobre todo en la novela Ilusiones perdidas. Allí Lucien de Rubempré llega desde el mundo rural a la ciudad, en busca de éxito. Tiene el apoyo de una dama rica, más tarde del diabólico Vautrin. Es notable que cuando se ocupa del pintor homosexual y drogadicto Alfredito, al que mira con ternura, vuelva a mencionar estos personajes. Su ruina en ese mundo de invertidos y degenerados lo lleva al suicidio, pero el escritor es capaz de conmoverse con su dolor. 
El personaje central de la trilogía es Manuel Alcázar, quien llega a Madrid, a una ciudad que ha crecido mucho y que ha acumulado personajes dolientes tanto en el centro degradado como en los suburbios miserables. Posible degenerado por herencia y medio, su padre maquinista alcoholizado, recuerda al personaje de $L a$ bestia humana. Es paseado por los ambientes madrileños, pensiones y prostíbulos, corralas y suburbios, casas ricas y nobiliarias, imprentas y periódicos, casas de artistas y al fin lugares de trabajo. Como en Zola, no se trata sólo de la mala vivienda, de los lugares de placer y bebida, también los lugares de trabajo -como esas fábricas que representan monstruos-forman un medio que junto a la herencia degeneran a sus poblaciones. Se encuentra con los miserables personajes de estas ciudades que atraían y empobrecían campesinos, de forma semejante a como sucede hoy con la emigración. El buen salvaje de Rousseau es degradado por la civilización.

No todo es sin embargo bajeza. Algunos personajes son capaces de mostrar en sus páginas la dignidad del hidalgo, o la preocupación por la degradación del medio, como el trapero. En un inciso, podemos decir que hasta un grafitero aparece en sus páginas. Nos paseará por casas de artistas, también por reuniones y discursos anarquistas, temas que siempre aparecen en sus novelas: ni bohemia ni política extremas le son gratas. El anarquismo podrá ser espiritual o revolucionario, también criminal y degenerado, tema que nos llevará hasta el tercer tomo de la trilogía, titulado Aurora roja. Pero sobre todo se encuentra en sus páginas la marginación, la estigmatización de muchos de los personajes. Así el chico golfo, como el que llama el Bizco, que es presentado como el criminal nato lombrosiano. Cercano al salvaje, al primitivo, a los animales, lujurioso, cruel y violento, maltrata a la mujer, delinque y acaba asesinando. Incluso algunas formas de expresión, como su lenguaje o como sus tatuajes muestran esta criminalidad, este primitivismo.

No es extraña la aparición de estos temas, pues eran frecuentes en la sociedad española del momento. El laboratorio de criminología permitía a Giner, Salillas, Simarro, Bernaldo de Quirós discutir estos problemas, se ponía en marcha el reformatorio de Alcalá, el tribunal tutelar de menores más tarde. Un discípulo de Lombroso, A. Niceforo escribía La mala vita a Roma, que C. Bernaldo de Quirós y J. M. ${ }^{a}$ Llanas seguirán en La mala vida en Madrid. El niño golfo se patologizaba en manos de legistas y psiquiatras, de la valía de Sanchis Banús, como ha mostrado Rafael Huertas. Zola desarrollaba todos estos personajes y situaciones en su gran friso familiar, con novelas como El vientre de París.

Otro de sus temas principales es el de la prostitución, sus visitas a salas de venéreas le impactarán, viendo el dolor y el sufrimiento que la sexualidad y la pobreza pueden conllevar. Para Lombroso es la equivalente del hombre delincuente la mujer prostituta, que arrastra rasgos de atavismos en su ambiente mise- 
rable. Las mismas características son mostradas por los estudiosos y por el novelista, enfermedades y deformaciones, lenguajes y vestimentas, pobreza y delito. Y la noche, sobre todo la noche, en que se mueven todos estos personajes, en ella empieza y termina La busca, primera entrega en la que Alcázar decide dedicarse al trabajo y al día. Su matrimonio, su trabajo serán camino de salvación, mientras que su hermano artista, inmerso como él en el ambiente del anarquismo, perecerá en posteriores páginas.

\section{El hombre de genio}

Nadie escapa por tanto al peligro de la degeneración, ni siquiera aquellos hombres que la sociedad considera superiores. Mucha tinta ha corrido sobre el carácter morboso, o al menos distinto, del artista y el sabio. Ya Aristóteles señala alguna peculiaridad en el hombre creador, que se unió al humor melancólico. La escuela de Morel y Magnan -incluyendo a Lombroso- consideró esta distinción como una neurosis, una degeneración o algún tipo de enfermedad. Zola describe al artista enfermo y fracasado en L'œuvre. Lo interesante es que esos mismos personajes que eran estigmatizados, admitieron a veces con gusto esta calificación, considerándola una distinción meritoria. En Baroja las citas a Huarte de San Juan y su Examen de ingenios son reveladoras de la aceptación de orígenes patológicos y somáticos del arte o la sabiduría. Él mismo parece retratarse con gusto en estos marcos, lo que no era nada raro, pues el arte de la decadencia tenía éxito en Europa. El mismo Nietzsche en su Ecce homo se muestra como un nuevo dios que ha dado la vida por los hombres, que ha sufrido y ha sido injuriado y condenado en su papel de redentor. Si no Cristo, al menos aceptaría ser Prometeo. Y algún personaje barojiano nos recuerda el sacrificio y la muerte del poeta Max Estrella.

Pío Baroja se retrata a sí mismo en La sensualidad pervertida, novela de 1920, tal como se verá mejor en sus Memorias, iniciadas en 1941. Todos los adjetivos que aplica a Luis Murguía, ese escritor diletante en que se refleja, le cuadran bien: sentimental y cínico, melancólico y cerebral, quijote e hidalgo, débil y fatalista... sin duda es un «pequeño buscador de almas», que se ha dejado llevar por el «placer melancólico del recuerdo». Tiene una extremada sensibilidad psíquica y sensorial, «el más pequeño contacto con la vida española me hacía daño». La familia -que proporciona protección y deformación- presenta anomalías, la educación es desagradable. Es llevado por distintos pueblos y ciudades, sus buenas condiciones (fe, honradez, ingenuidad infantil) chocan con las normas de los antepasados, representados por las fuerzas vivas, los clérigos y militares, los ricos y aristócratas, los políticos y magistrados... Es una novela de viaje interior y exte- 
rior, está en la trilogía de 'Las ciudades'. Baroja gusta mucho de desplazamientos rápidos y largos en sus novelas, además de las dedicadas a aventuras, se pueden recordar los bruscos viajes de la rusa Sacha en El mundo es ansí.

El principal argumento de La sensualidad pervertida es la entrada en la pubertad, la difícil sexualidad del adolescente: «Lo corrompido que es uno de chico». También el papel esencial de la sexualidad en la formación del individuo, así en la del artista. Pasa revista a las diversas posibilidades de iniciación sexual en la época, con criadas, prostitutas, jóvenes engañadas, pero también con mujeres liberadas, como casadas, extranjeras, o bien modistas y bordadoras. Su fuerte instinto sexual y su sensible delicadeza lo llevan hacia una sensualidad patológica. No es sino la representación de la vida sexual en la España reprimida y frustrada. Es la lucha personal de la voluntad contra los instintos, en que termina prefiriendo el sueño a la vida. Elegirá el camino ascético, el estoicismo. Las lecturas de Schopenhauer y santa Teresa (también san Ignacio, a quien ataca) están presentes en su vida.

Sus intenciones en la vida, de personaje y autor, son mantener la independencia y enterarse de la vida. La sexualidad es una necesidad que limita la independencia, para conservar ésta es necesario dinero o caer en el matrimonio, del que abomina pues supone la vieja organización instintiva de los antepasados. Para enterarse de qué va la vida, el hombre de genio es personaje peligroso. Con ironía nos dice que antes se interesaba por el satanismo, la perversidad, la neurastenia, pero que no quiere las enfermedades de estos seres supuestamente superiores. En esa época los hombres quieren ser extraordinarios, los que saltan sobre su sombra son ridículos, quienes la llevan como al escudero son vulgares. Él elige el camino de la mediocridad, llevado por la razón, pero el camino es incierto. No le gustan los negocios ni la ciencia, el trabajo ni las carreras. Se separa de la bohemia, de las vanguardias, no gusta de los ismos que encuentra en París. Para estos falsos artistas, toda aberración de costumbres o sexual está permitida. Aquí nos introduce en el mundo bajo del arte, en sus sótanos, con esos creadores alcohólicos, o ese delicado Alfredito.

El amor debe limitarse a la pasión física, a la fisiología, liberando la poesía, el idealismo es para la ciencia y la filosofía. Él camina hacia la castidad, la abstención de carne y vino, recordemos a Kafka y a Nietzsche, para quienes el comer carne era signo de agresividad, triunfo y euforia. Quiere renunciar a las diversiones, conseguir la indiferencia estoica, dedicado a leer y saber. Sátiro degenerado por la filosofía y el vegetarianismo, se define, fauno reumático que ha leído un poco a Kant. En la lucha entre la tradición de religión y moral que preside el medio ambiente español, quiere el equilibrio de espíritu mantenido con orgullo y rencor, en fin una vida tranquila. Esa «águila vegetariana», reconoce su fracaso con la mujer, esa naturaleza en que no ha arado de la manera en que Miguel Hernández dirá haber gozado. Añora los hijos, añora la vida... pero la contempla y embellece. 
La misma tónica se había pergeñado en 1902 en Camino de perfección. El estudiante de medicina, aficionado artista, muestra claros signos de degeneración. Pintor aficionado, estudiante de medicina, muestra su peculiaridad guardando recuerdos de los cadáveres del teatro anatómico. Llevando a sus espaldas una herencia problemática, más una educación siniestra con los escolapios, recorre paisajes, pueblos y ciudades en busca de experiencias morbosas. Muerte y cementerios, castillos y ruinas, noche y extraños personajes, enfermedades y alteraciones del sentimiento y la sexualidad. La decadencia y la degeneración son sus acechantes compañeras. Es, una vez más, el viaje sentimental, diferente de sus novelas de aventuras. Un alemán lo anima al ejercicio, como San Martín en el tribunal de su tesis. Termina en tierras valencianas, enamorado de la naturaleza y el trabajo, de su mujer y su hijo. Lo educará en los instintos naturales y salvajes, la vida y el trabajo del campo, en fin la posesión de la tierra. Vivirá en la naturaleza lejos de los pedagogos -recordemos al Unamuno de Amor y pedagogía- que lo perturbarían con estudios e ideas, con religiones inútiles y tristes. Sus instintos libres lo convertirán en león o águila, no en esa águila vegetariana en que se ha convertido él mismo, dirá atribuyendo ese experimento a Spallanzani, quien habría nutrido rapaces con pan y palomas con carne.

Pero si a la larga se convirtiese en un monstruo -no en el hijo enfermo de Torquemada- seguirá adelante, actuará por «encima de la ley», con el «gesto gallardo del antiguo jefe de una devastadora horda». Sin duda, si en sus pesimismos y fracasos influía Schopenhauer, acá están sus imágenes tomadas con fidelidad de Nietzsche. El Superhombre también puede ser el futuro. Pero igual que se burla de esta idea poniendo este nombre de mote a algún personaje de 'La lucha por la vida', también termina con su genial ironía. La suegra, la madre de Dolores, cose en los pañales del niño una página del Evangelio. Una ironía contraria se encuentra en las páginas finales de El árbol de la ciencia; tras el matrimonio feliz con Lulú, bordadora que se ha estabilizado con una tienda de confección, viene la desgracia. Mueren madre e hijo, y Andrés Hurtado toma «aconitina cristalizada de Duquesnel», nos dice con petulancia el médico Baroja. Era un epicúreo, un aristócrata sin fuerza para vivir. Pero -se dice de forma solemne y profética en el final- había en él algo de precursor. Tal vez anunciaba el siglo de la ciencia, tal vez el convencimiento de que sólo la nueva vida consiente la persistencia de la vida. Al modo orteguiano era el XX el siglo de la naturaleza, del resurgir de la carne y la vida.

* Conferencia en la Universidad Carlos III, con ocasión del 50 aniversario de la muerte de Baroja. Correspondencia: José Luis Peset, Instituto de Historia, CSIC, Madrid.

** Fecha de recepción: 2-XI-2006. 